\title{
Morfologia polínica das espécies arbóreas de Apocynaceae do Estado de Santa Catarina, Brasil
}

\author{
Ortrud Monika Barth ${ }^{1,3}$ e Cynthia Fernandes Pinto da Luz ${ }^{2}$
}

Recebido: 12.12.2007; aceito: 30.10.2008

\begin{abstract}
Pollen grain morphology of the arboreal Apocynaceae in the state of Santa Catarina, Brazil). The pollen morphology of seven species belonging to three genera of the Apocynaceae family and occurring in the state of Santa Catarina, Brazil, was considered in the present paper. The pollen grains of three species of Aspidosperma [A. australe Muell. Arg., A. pyricollum Muell. Arg. e A. ramiflorum Muell. Arg.] correspond to a same pollen type, and present no specific morphological features. Similar observation was made of the three species of Peschiera (Peschiera cf. australis (Muell. Arg.) Miers, Peschiera catharinensis (DC) Miers e Peschiera aff. histrix (Stend.) DC. Rauvolfia sellowii Muell. Arg. presents a characteristic pollen morphology of oblate and brevicolpate pollen grains. The occurrence of a vestibulum in the apertural area of the pollen grains is a attribute of all species examined.
\end{abstract}

Key words: Apocynaceae, palynology, trees

RESUMO - (Morfologia polínica das espécies arbóreas de Apocynaceae do Estado de Santa Catarina, Brasil). Foi analisada no presente trabalho a morfologia polínica de sete espécies pertencentes a três gêneros da família Apocynaceae ocorrentes no Estado de Santa Catarina, Brasil. Os grãos de pólen das três espécies de Aspidosperma [A. australe Muell. Arg. A. pyricollum Muell. Arg. e A. ramiflorum Muell. Arg.] correspondem a um mesmo tipo polínico e não apresentam características morfológicas específicas. O mesmo fato ocorre com as três espécies do gênero Peschiera (Peschiera cf. australis (Muell. Arg.) Miers, Peschiera catharinensis (DC) Miers e Peschiera aff. histrix (Stend.) DC. Rauvolfia sellowii Muell. Arg. apresenta uma morfologia polínica característica por meio de grãos de pólen oblatos e brevicolpados. Característico para todas as espécies examinadas é a formação de um vestíbulo na área apertural dos grãos de pólen.

Palavras-chave: Apocynaceae, árvores, palinologia

\section{Introdução}

Apocynaceae é uma família formada essencialmente de plantas tropicais, algumas subtropicais, compreendendo mais de 150 gêneros e de 1.000 espécies (Pire 1989). Pelo seu hábito apresentam árvores, arbustos e lianas, raramente ervas. As plantas contêm látex e apresentam grau variado de toxicidade. Algumas são pioneiras, outras preferem ambientes mais úmidos podendo ser higrófitas seletivas. Ocorrem desde a Região Amazônica até o Sul do Brasil.

Segundo Markgraf (1968) e Lorenzi (1992), as Apocynaceae estão presentes principalmente na vegetação de Mata Atlântica; algumas espécies ocorrem na Mata Branca do alto rio Uruguai. Há três gêneros apresentando plantas com porte arbóreo. Aspidosperma, seletivas hidrófitas, compreende as perobas, de porte frondoso e de alto valor comercial. $A$. australe Muell. Arg. é pioneira na floresta subtropical das Bacias dos rios Paraná e Uruguai, na mata branca, raramente ocorrendo na mata pluvial da encosta atlântica do Sul do Brasil; é freqüente nas capoeiras do oeste do estado e nos sub-bosques dos pinhais. A. camporum Muell. Arg. é rara no estado de Santa Catarina e encontrada em associações secundárias. A. pyricollum Muell. Arg. cresce em todas as partes do Estado. A. ramiflorum Muell. Arg. é exclusiva da mata pluvial da encosta atlântica. O gênero Peschiera é de porte mais arbustivo ou de arvoreta. P. australis (Muell. Arg.) Miers, pouco frequiente, faz parte da mata subtropical da bacia do rio Uruguai, estando presente em capoeiras e clareiras de solos úmidos, sendo heliófita. P. catharinensis (DC) Miers faz parte da vegetação da mata atlântica e raramente ocorre no vale do rio do Peixe e na bacia do rio Uruguai. Rara no Estado de Santa Catarina, P. histrix (Stend.) DC. prefere as associações vegetais secundárias. Uma só espécie do gênero, Rauvolfia sellowii Muell. Arg. é

1. Instituto Oswaldo Cruz, Fiocruz, Av. Brasil 4365, 21040-900 Rio de Janeiro, RJ, Brasil

2. Instituto de Botânica, Caixa Postal 3005, 01061-970 São Paulo, SP, Brasil

3. Autor para correspondência: barth@ioc.fiocruz.br 
rara na porção oeste do Estado, na mata, em capoeirões e pastos.

A morfologia do pólen de Apocynaceae é relativamente bem conhecida. Estudos taxonômicos e filogenéticos baseados na Palinologia foram explorados por Nilsson (1990) e Nilsson et al. (1993). Vários gêneros e numerosas espécies de Apocynaceae da Argentina tiveram seu pólen analisado por Pire (1989). Do Brasil há dados sobre o pólen de Apocynaceae de uma restinga do Estado do Rio de Janeiro (Moreira et al. 2004) e de uma área preservada em São Paulo (Luz et al. 2007), além da morfologia polínica constante de compêndidos palinológicos, tais como Erdtman (1952) e no seriado do cerrado (Marques \& Melhem 1966).

Atividades ecológicas e ambientais, visando à preservação de espécies e indagando sobre vegetações que se sucederam durante o período Quaternário, demandam por um conhecimento detalhado da estrutura polínica, já que o pólen, além de resistir à degradação ao longo do tempo, fornece informações que levam à sua origem, o táxon vegetal, bem como à caracterização ecológica do seu meio ambiente. No presente estudo serão fornecidas as características morfológicas dos grãos de pólen das espécies arbóreas de Apocynaceae ocorrentes no Estado de Santa Catarina.

\section{Material e métodos}

A listagem das espécies abordadas no presente trabalho foi retirada de Markgraf (1968). O material polínico foi obtido de exsicatas depositadas no Herbário do Jardim Botânico do Rio de Janeiro (RB) e no Herbário do Museu Nacional do Rio de Janeiro (R), conforme abaixo especificado, já que o Herbário "Barbosa Rodrigues" atualmente não o disponibiliza, constando das seguintes espécies: Aspidosperma australe Muell. Arg. - Brasil. SANTA Catarina: Oliveira, 24-X-1938, G. Mendes de Magalhães s.n. (R35225); Catanduva, Smith \& Klein 12985 (R127248). Aspidosperma pyricollum Muell. Arg. - Brasil. Rio DE JANEIRO: restinga de Cabo Frio, $C$. Poland 6673 (RB82070). Aspidosperma ramiflorum Muell. Arg. - Brasil. Rio DE JANEIRO: Jardim Botânico, 25-VII-1946. David Azambuja s.n. (RB16366). Peschiera cf. australis (Muell. Arg.) Miers - Brasil. Rio De JaneIro: São Pedra D'Aldeia, Gomes \& Burle Max 1179 (RB107425). Peschiera catharinensis (DC.) Miers - Brasil. Santa Catarina: Rio do Peixe, Smith \& Klein 12944 (R128538). Peschiera aff. histrix (Stend.)
DC. - Brasil. Rio de Janeiro: Maricá, C. Farney \& Andreatta, Lima, D. Araújo 368 (RB238494). Rauvolfia sellowii Muell. Arg. - Brasil. PARANÁ: Foz do Iguaçu, J.F. Kuhlmann s.n. (RB57720).

Não foi possível obter material polínico de Aspidosperma camporum Muell. Arg.

O pólen de todas as exsicatas foi submetido à acetólise (Erdtman 1952), incluído em gelatina glicerinada; as preparações formam vedadas com parafina. Parte do material acetolisado de cada exsicata foi parcialmente desidratado em etanol a $70 \%$, colocado sobre os suportes do microscópio eletrônico de varredura (MEV), secado e recoberto por fina camada $(15 \mathrm{~nm})$ de ouro.

Fotomicrografias de luz fotônica (ML) foram obtidas usando um microscópio Axiophot, Zeiss, acoplado com câmara analógica Sony, processadas digitalmente no programa AxioVision 3.0, Zeiss. Micrografias eletrônicas foram obtidas usando um MEV DSM-940, Zeiss. Mensurações foram realizadas usando tambor micrométrico, Zeiss Jena: $\mathrm{n}=25$ para os diâmetros polar e equatorial e $\mathrm{n}=10$ para as demais medidas. A terminologia usada está baseada em Barth \& Melhem (1988).

\section{Resultados}

Seguem as descrições da morfologia polínica de seis espécies arbóreas ocorrentes no Estado de Santa Catarina. As dimensões dos grãos de pólen são apresentadas nas tabelas 1 e 2 .

Aspidosperma australe Muell. Arg. (R35225)

Figuras 1-9

Grãos de pólen médios, isopolares, suboblatos a oblato-esferoidais, de âmbito ondulado, 5(-6)-colporados, 5(-6)-pseudocolpados, longicolpados, psilados, sexina de espessura variável, nexina delgada.

Comentários: Tamanho e forma dos grãos de pólen são bastante variáveis, já que a nexina oferece pouca rigidez. Este fato leva ao enrugamento dos grãos de pólen mascarando uma falsa ornamentação. Os colpos são estreitos, longos, com margem, apresentando ampla e bem definida área apertural reforçada pelo espessamento da sexina; nas partes entre as áreas aperturais e nos apocolpos a sexina tem aproximadamente a mesma espessura que a nexina. As endoaberturas são lalongadas, não apresentando reforços laterais, formando-se um vestíbulo entre elas e a sexina da área apertural. 
Tabela 1. Dados morfométricos dos grãos de pólen $(\mathrm{n}=25)$ : $\mathrm{P}=$ eixo polar $(\mu \mathrm{m}) ; \mathrm{E}=$ eixo equatorial $(\mu \mathrm{m})$; Ev.p. = eixo equatorial em vista polar $(\mu \mathrm{m}) ; \mathrm{P} / \mathrm{E}=$ índice que define a forma dos grãos de pólen. No parêntesis = faixa de variação.

\begin{tabular}{|c|c|c|c|c|c|}
\hline \multirow{2}{*}{ Táxons } & \multicolumn{4}{|c|}{ Dados morfométricos } & \multirow{2}{*}{ Forma } \\
\hline & $P$ & $\mathrm{E}$ & Ev.p. & $\mathrm{P} / \mathrm{E}$ & \\
\hline $\begin{array}{l}\text { Aspidosperma australe } \\
\text { Muell. Arg.(R35225) }\end{array}$ & $\begin{array}{c}40,1 \\
(34,0-44,6)\end{array}$ & $\begin{array}{c}45,1 \\
(37,7-49,2)\end{array}$ & $\begin{array}{c}45,3 \\
(40,0-51,5)\end{array}$ & 0,89 & suboblato a oblato-esferoidal \\
\hline $\begin{array}{l}\text { A. australe Muell. Arg. } \\
\text { (R127248) }\end{array}$ & 40,7 & 40,9 & 43,4 & 0,99 & oblato-esferoidal \\
\hline A. pyricollum Muell. Arg. & $\begin{array}{c}34,0 \\
(27,0-48,6)\end{array}$ & $\begin{array}{c}36,7 \\
(30,6-46,8)\end{array}$ & $\begin{array}{c}42,0 \\
(30,8-52,0)\end{array}$ & 0,93 & oblato-esferoidal \\
\hline A. ramiflorum Muell. Arg. & $\begin{array}{c}33,7^{*} \\
(30,4-41,4)\end{array}$ & $\begin{array}{c}40,2^{*} \\
(32,7-48,8)\end{array}$ & $\begin{array}{c}40,3 \\
(34,0-54,7)\end{array}$ & 0,84 & suboblato \\
\hline $\begin{array}{l}\text { Peschiera } \text { cf. australis } \\
\text { (Muell. Arg.) Miers }\end{array}$ & $\begin{array}{c}30,6 \\
(26,1-36,9)\end{array}$ & $\begin{array}{c}41,6 \\
(34,2-51,3)\end{array}$ & $\begin{array}{c}44,9 \\
(36,0-61,2)\end{array}$ & 0,74 & oblato \\
\hline $\begin{array}{l}\text { P. catharinensis (DC.) } \\
\text { Miers }\end{array}$ & $\begin{array}{c}40,9 \\
(32,7-49,2)\end{array}$ & $\begin{array}{c}45,5 \\
(38,2-50,1)\end{array}$ & $\begin{array}{c}43,7 \\
(37,7-50,6)\end{array}$ & 0,90 & suboblato \\
\hline$P$. aff. histrix (Stend.) DC & $\begin{array}{c}46,8 \\
(28,3-59,7)\end{array}$ & $\begin{array}{c}48,4 \\
(29,6-64,3)\end{array}$ & $\begin{array}{c}38,1 \\
(28,8-47,7)\end{array}$ & 0,97 & oblato esferoidal \\
\hline $\begin{array}{l}\text { Rauvolfia sellowii Muell. } \\
\text { Arg. }\end{array}$ & $\begin{array}{c}48,7 * \\
(41,4-60,3)\end{array}$ & $\begin{array}{c}52,5^{*} \\
(40,5-58,5)\end{array}$ & $\begin{array}{c}52,5 \\
(45,0-60,3)\end{array}$ & 0,69 & oblato \\
\hline
\end{tabular}

$* \mathrm{n}=12$

As características morfológicas de Aspidosperma australe Muell. Arg. (R127248), Aspidosperma pyricollum Muell. Arg. e Aspidosperma ramiflorum Muell. Arg. (Fig. 10 ) conferem com as do espécimen anterior.

Peschiera cf. australis (Muell. Arg.) Miers

Figuras 11 e 19

Grãos de pólen médios, isopolares, de âmbito circular a subtriangular, suboblatos, 3(-4)-colporados, brevicolpados, cólporo compr. ca. 29,0 $\mu \mathrm{m}$, larg. ca. $8,5 \mu \mathrm{m}$, endoabertura altura ca. 7,4 $\mu \mathrm{m}$, larg. ca. 22,0 $\mu \mathrm{m}$; psilados, sexina de espessura variável, nexina delgada.

Comentários: O tamanho dos grãos de pólen é bastante variável em função das aberturas. Os curtos colpos, sem margens marcantes, sobrepõemse às endo-aberturas extremamente lalongadas que não apresentam reforços laterais, formando-se um amplo vestíbulo em toda parte mediana da área apertural.

\section{Peschiera catharinensis (DC.) Miers}

Figuras 12-18

Grãos de pólen médios, isopolares, de âmbito circular a subtriangular, suboblatos, 3(-4)-colporados, brevicolpados, psilados, sexina de espessura variável, nexina delgada.

Tabela 2. Dados morfométricos dos grãos de pólen $(\mathrm{n}=10): \mathrm{S}=$ espessura da sexina $(\mu \mathrm{m}), \mathrm{N} 2=$ espessura da nexina $2(\mu \mathrm{m})$.

\begin{tabular}{lcc}
\hline Táxons & $\mathrm{S}$ & $\mathrm{N} 2$ \\
\hline $\begin{array}{l}\text { Aspidosperma australe Muell. } \\
\text { Arg.(R35225) }\end{array}$ & até 1,5 & 0,4 \\
A. australe Muell. Arg. (R127248) & & \\
& até 1,5 & 0,4 \\
A. pyricollum Muell. Arg. & 1,1 & 0,4 \\
A. ramiflorum Muell. Arg. & 1,1 & 0,4 \\
Peschiera cf. australis (Muell. Arg.) & & \\
Miers & 1,1 & 0,4 \\
P. catharinensis (DC) Miers & 1,7 & 0,7 \\
P. aff. histrix (Stend.) DC. & 1,2 & 0,5 \\
Rauvolfia sellowii Muell. Arg. & 2,0 & 0,6 \\
\hline
\end{tabular}



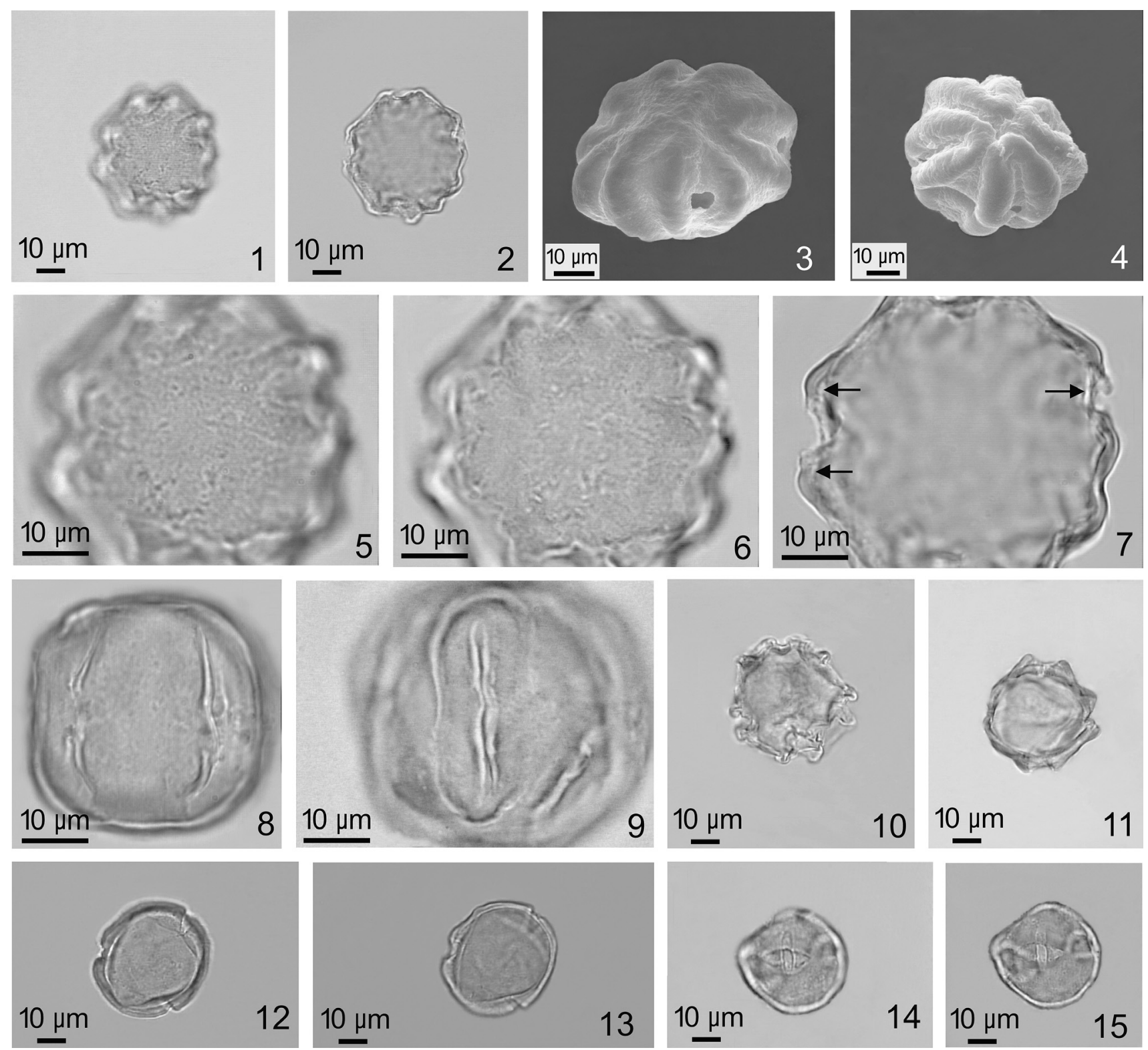

Figuras 1-15. Grãos de pólen de espécies de Aspidosperma e Peschiera. 1-9. Aspidosperma australe Muell. Arg. 1-7. Vista polar. 1. Superficie, ML. 2. Corte óptico, ML. 3. Endoabertura, MEV. 4. Áreas aperturais em um grão parcialmente distendido, MEV. 5. Detalhe da ornamentação no apocolpo em foco alto, ML. 6. Detalhe da ornamentação no apocolpo em foco baixo, ML. 7. Corte óptico detalhando vestíbulos (setas) nas áreas aperturais, ML. 8-9. Vista equatorial. 8. Mesocolpo, superfície, ML. 9. Área apertural e colpo, ML. 10. Aspidosperma ramiflorum Muell. Arg., vista polar: grão de pólen não distendido, ML. 11. Peschiera cf. australis (Muell. Arg.) Miers., vista polar: grão de pólen 4-colporado, ML. 12-15. Peschiera catharinensis (DC.) Miers. 12-13. Vista polar. 12. Apocolpo, ML. 13. Corte óptico, ML. 14-15. Vista equatorial. 14. Área apertural com colpo e endoabertura, ML. 15. Corte óptico, ML. 


\section{Peschiera aff. histrix (Stend.) DC.}

Grãos de pólen médios, isopolares, de âmbito circular a subtriangular, oblato esferoidal, 3(-4)colporados, brevicolpados, cólporo compr. ca. 24,5 $\mu \mathrm{m}$, larg. ca. 5,5 $\mu \mathrm{m}$, endoabertura altura ca. 10,3 $\mu \mathrm{m}$, larg. ca. 22,0 $\mu \mathrm{m}$; psilados, sexina de espessura variável, nexina delgada.

Rauvolfia sellowii Muell. Arg.

Figuras 20-27

Grãos de pólen grandes, isopolares, de âmbito circular, suboblatos, 3-colporados, brevicolpados, cólporo compr. ca. 10,6 $\mu \mathrm{m}$, larg. ca. 3,0 $\mu \mathrm{m}$; psilados, sexina mais espessa do que a delgada nexina.

Comentários: O tamanho e a forma dos grãos de pólen são pouco variáveis. Os colpos, sem margens marcantes, são estreitos e muito curtos. Aárea apertural é delimitada pela formação de um amplo vestíbulo. As endoaberturas são muito pequenas, ligeiramente lolongadas e muito pouco evidenciadas.

\section{Discussão}

Segundo as características morfológicas dos grãos de pólen das sete espécies de Apocynaceae acima descritas, sobressai a uniformidade ao nível de gênero e a caracterização destes por diferenças significativas.

Em Aspidosperma, devido à fragilidade da estrutura da exina, ocorrem formas subprolatas até suboblatas após seu processamento de fossilização artificial. Quatro a seis colpos longos e estreitos, com margens, e amplas áreas aperturais com formação de vestíbulos e com espessamentos de sexina são as características mais marcantes.

Em Peschiera, a forma dos grãos de pólen é mais constante, variando entre suboblato a oblato. Colpos curtos, relativamente largos e endoaberturas lalongadas e mais expressivas formando vestíbulos alongados ao longo da faixa equatorial, caracterizam este gênero.

Rauvolfia sellowii possui grãos de pólen bem maiores do que nos dois gêneros anteriores, sempre posicionados em vista polar, de colpos curtíssimos e marcante vestíbulo na área apertural.

As superfícies não apresentam ornamentações características, em todos os espécimens são psiladas, raramente algumas perfurações podem ser detectadas. Ondulações da exina, às vezes muito pronunciadas em Aspidosperma, são resultado da fragilidade estrutural dos grãos de pólen em relação ao seu processamento químico ou podem ser atribuídas a material ainda jovem que não tenha atingido a resistência de uma exina adulta. Columelas subtectais não são evidenciáveis em microscopia de luz fotônica. Irregularidades na linha de face interna das nexinas nas áreas aperturais são freqüientes em todos estes gêneros.

A formação de um vestíbulo é característica para todas as espécies examinadas. De acordo com o tamanho das áreas aperturais e as dimensões de colpos e endoaberturas, este vestíbulo que se forma como uma cavidade pelo afastamento entre sexina e nexina, pode atingir dimensões consideráveis. Em Aspidosperma, adicionalmente, ocorre um forte espessamento da sexina sobre estes vestíbulos, marcando ainda melhor as áreas aperturais. Devido às dimensões destas e à diminuição da espessura da sexina entra as mesmas, a adoção do termo pseudocolpo - uma área entre os colpos, de estrutura mais frágil, mas sem função apertural - parece ser adequada, conforme anteriormente já citado por Pire (1989).

Os grãos de pólen de dois outros espécimens de Aspidosperma australe foram descritos por Pire (1989) e um de A. pyricollum por Moreira et al. (2004). As características morfológicas conferem, exceto os tamanhos dos grãos de pólen. O mesmo ocorre quanto aos cinco espécimens de Peschiera australis examinados por Pire (1989), bem como aos espécimens de Rauvolfia sellowii examinados por Pire (1989) e Luz et al. (2007). Os dois espécimens de Peschiera australis examinados por Luz et al. (2007) apresentaram também grãos de pólen com duas aberturas.

\section{Agradecimentos}

Agradecemos ao Conselho Nacional de Desenvolvimento Científico e Tecnológico (CNPq) pelo apoio financeiro por meio de bolsa individual de pesquisa concedida à primeira autora.

\section{Literatura citada}

Barth, O.M. \& Melhem, T.S. 1988. Glossário ilustrado de Palinologia. Editora Unicamp, Campinas.

Erdtman, G. 1952. Pollen morphology and plant taxonomy - Angiosperms. Almqqvist \& Wicksell, Stockhom.

Lorenzi, H. 1992. Árvores brasileiras. Editora Plantarum, Nova Odessa.

Luz, C.F.P., Albanese, F.J. \& Corrêa, A.M.S. 2007. Flora polínica da Reserva do Parque Estadual das 

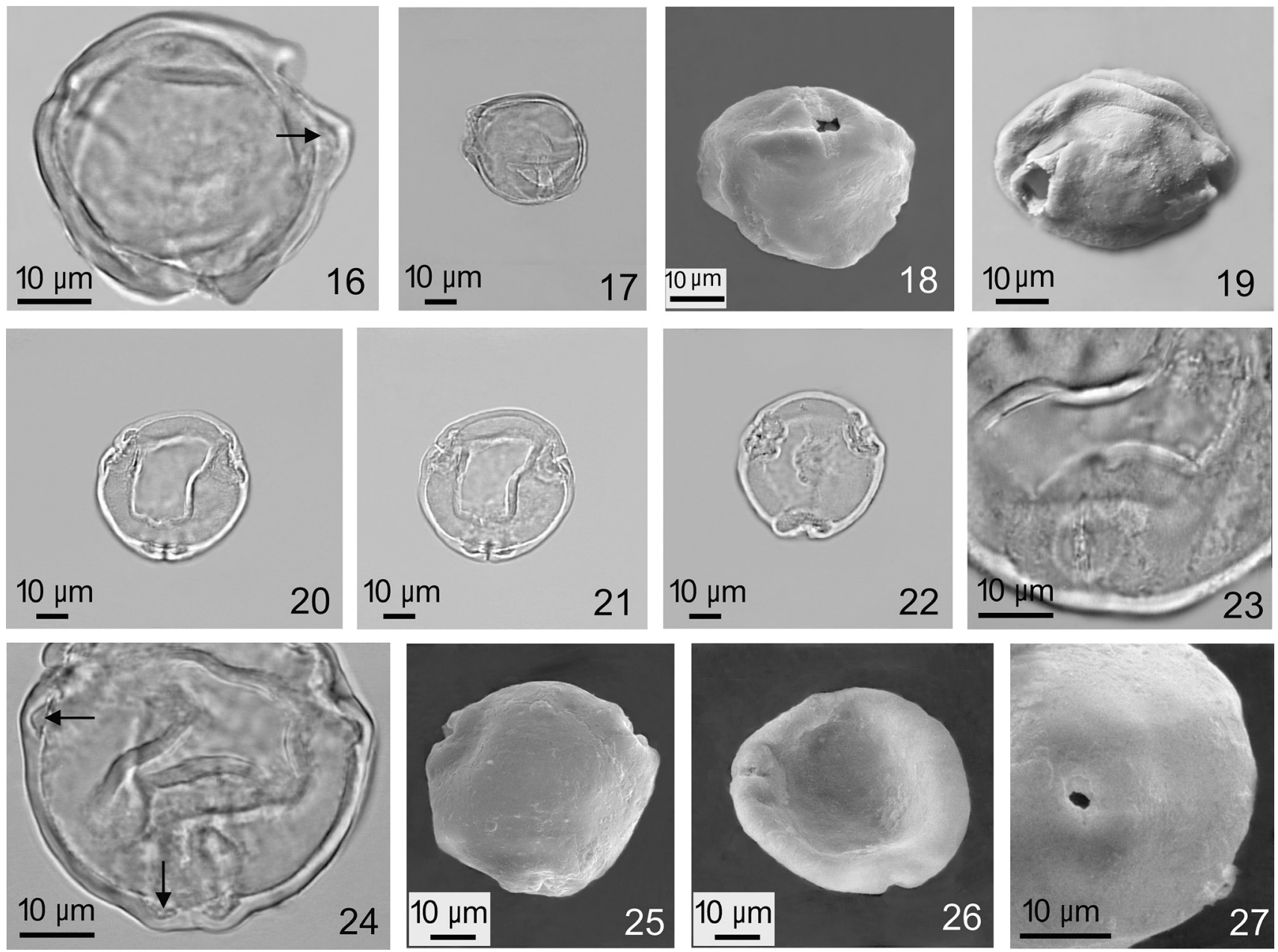

Figuras 16-27. Grãos de pólen de espécies de Peschiera e Rauvolfia. 16-18. Peschiera catharinensis (DC) Miers. 16. Vista polar, corte transversal pela exina e vestíbulo (seta), ML. 17-18. Vista oblíqua. 17. área apertural, ML. 18. área apertural, MEV. 19. Peschiera cf. australis (Muell. Arg.) Miers., vista oblíqua: área apertural com colpo e endoabertura, MEV. 20-27. Rauvolfia sellowii Muell. Arg. Vista polar. 20. Superfície com área polar invaginada, ML. 21. Corte óptico com área polar invaginada, ML. 22. Aspecto característico de um grão de pólen não totalmente distendido, corte óptico, ML. 24. Corte óptico detalhando vestíbulos (setas) nas áreas aperturais, ML. 25. Apocolpo, grão de pólen distendido, MEV. 26. Apocolpo em grão de pólen não distendido, MEV. 23 e 27. Vista equatorial. 23. Área apertural aproximadamente circular, colpo curto e endoabertura lolongada, ML. 27. Área apertural, colpo curto e centro da endoabertura, MEV.

Fontes do Ipiranga (São Paulo, Brasil). Família 134 Apocynaceae. Hoehnea 34: 417-426.

Markgraf, F. 1968. Apocináceas. In: (PR Reitz, editor). Flora Ilustrada Catarinense. I Parte: As Plantas, Fascículo: APOC. Itajaí, Brasil. p.1-112.

Marques, M. \& Melhem, T.S. 1966. Pollen grains of plants of the "cerrado" - XI - Apocynaceae. Anais da Academia Brasileira de Ciências 38: 371-378.

Moreira, F.F., Mendonça, C.B.F., Pereira, J.F. \& Gonçalves-Esteves, V. 2004. Palinotaxonomia de espécies de Apocynaceae ocorrentes na restinga de
Carapebus, Carapebus, RJ, Brasil. Acta Botanica Brasílica 18: 711-721.

Nilsson, S. 1990. Taxonomic and evolutionary significance of pollen morphology in the Apocynaceae. Plant System Evolution (Supplement 5): 91-102.

Nilsson, S., Endress, M.E. \& Grafstroem, E. 1993. On the relationship of the Apocynaceae and Periplocaceae. Grana (Supplement 2): 3-20.

Pire, S.M. 1989. Morfologia polínica de las Apocynaceae de la Argentina. Boletin de la Sociedad Argentina de Botánica 26: 69-84. 